\title{
Gambaran kepekaan Escherichia coli dari peternakan ayam broiler di Desa Bojongkerta Kabupaten Sukabumi terhadap antibiotik
}

\author{
Merlia Andriyani ${ }^{1}$, Usamah Afiff ${ }^{2, *}$, Risa Tiuria $^{3}$ \\ ${ }^{1}$ Program Sarjana Fakultas Kedokteran Hewan, Institut Pertanian Bogor \\ ${ }^{2}$ Divisi Mikrobiologi Medik, Departemen Ilmu Penyakit Hewan dan Kesehatan Masyarakat Veteriner, \\ Fakultas Kedokteran Hewan, Institut Pertanian Bogor \\ ${ }^{3}$ Divisi Parasitologi dan Entomologi Kesehatan, Departemen Ilmu Penyakit Hewan dan Kesehatan Masyarakat \\ Veteriner, Fakultas Kedokteran Hewan, Institut Pertanian Bogor
}

\begin{abstract}
ABSTRAK: Masalah resistensi Escherichia coli (E. coli) terhadap antibiotik telah banyak dilaporkan. Peningkatan kasus resistensi bakteri terhadap antibiotik dapat dilihat dari banyaknya laporan bahwa terdapat antibiotik yang sudah tidak efektif lagi terhadap suatu bakteri patogen. Pola penggunaan antibiotik di Indonesia dan negara-negara lain semakin meningkat dan banyak diantaranya masih digunakan secara tidak tepat. Tujuan penelitian ini adalah mempelajari gambaran kepekaan E. coli dari ayam broiler terhadap sefpodoksim, sefoksitin, sulfametoksazol-trimetoprim, kolistin sulfat, seftizoksim, aztreonam, dan nitrofurantoin dari peternakan ayam broiler di Desa Bojongkerta Kabupaten Sukabumi Jawa Barat. Pengujian resistensi antibiotik menggunakan metode difusi cakram menurut Kirby-Bauer. Hasil uji kepekaan isolat E. coli menunjukkan bahwa isolat E.coli dalam penelitian ini telah resisten terhadap sefpodoksim, sefoksitin, sulfametoksazol-trimetoprim, seftizoksim, aztreonam, dan nitrofurantoin. Namun tidak menunjukkan hasil terhadap kolistin sulfat.
\end{abstract}

Kata kunci:

ayam broiler, Escherichia coli, resistensi antibiotik.

\section{- PENDAHULUAN}

Escherichia coli (E. coli) merupakan flora normal dalam pencernaan makhluk hidup yang keberadaannya juga memberikan dampak berupa infeksi. Infeksi E. coli umumnya diobati menggunakan antibiotik. Penggunaan antibiotik yang tidak tepat menyebabkan resistensi bakteri terhadap antibiotic. Resistensi bakteri dapat disebabkan oleh intensitas paparan pada suatu wilayah serta penggunaan antibiotik terus menerus (Refdanita et al. 2004).

E. coli telah banyak mengalami resistensi terhadap antibiotik golongan beta-laktam, fosfomisin dan quinolon (Noviana 2004). Menurut Erfianto (2014), dari 60 isolat $E$. coli dari feses sapi yang diuji terhadap antibiotik menunjukkan isolat telah resisten terhadap eritromisin dengan persentase sebesar $81,7 \%$, cefalotin $36,7 \%$, ampisillin $25 \%$, streptomisin 3,3\%, tetrasiklin 3,3\%, enrofloksasin $1,7 \%$, dan trimetoprim-sulfametoksasol $1,7 \%$. Resistensi bakteri E. coli terhadap antibiotik merupakan ancaman karena selain berdampak pada morbiditas dan mortalitas, juga memberi dampak negatif terhadap ekonomi dan sosial. Oleh sebab itu, perlu adanya pembaharuan data mengenai efektivitas antibiotik tertentu terhadap bakteri E. coli agar menjadi landasan terapi dalam penggunaan anti-biotik yang tepat dan bijak.

\section{- BAHAN DAN METODE}

Bahan: Sampel swab kloaka ayam broiler (30 sampel), media isolasi dan identifikasi $E$. coli, sefpodoksim $10 \mu \mathrm{g}$, sefoksitin $30 \mu \mathrm{g}$, sulfametoksazol-trimetoprim $25 \mu \mathrm{g}$, kolistin sulfat, seftizoksim $30 \mu \mathrm{g}$, aztreonam $30 \mu \mathrm{g}$, dan nitrofurantoin $300 \mu \mathrm{g}$. Isolasi dan Identifikasi Bakteri: Isolasi dan identifikasi bakteri mengacu pada Markey et al. (2013). Pengujian Kepekaan Antibiotik: Pengujian kepekaan antibiotik dilakukan dengan metode agar difusi menurut Kirby-Bauer. Analisis data: Analisis data dilakukan Secara deskriptif dan ditampilkan dalam bentuk tabel dan gambar. Hasil uji diinterpretasikan mengacu pada Clinical and Laboratory Standards Institute (CLSI) 2018.

\section{- HASIL DAN PEMBAHASAN}

Hasil yang menunjukkan karakteristik E.coli dari 30 sampel adalah 8 isolat. Uji kepekaan terhadap antibiotik pada Mueller Hinton Agar pada 8 isolat tersebut tersaji pada Gambar 1 dan Tabel 1.

Diterima: 25-01-2020 | Direvisi: 26-02-2020 | Disetujui: 28-02-2020 (C) 2020 CC-BY-SA. Ini adalah artikel Open Access yang didistribusikan berdasarkan ketentuan dari Creative Commons Attribution ShareAlike 4.0 International License (https://creativecommons.org/licenses/by-sa/4.0/). 


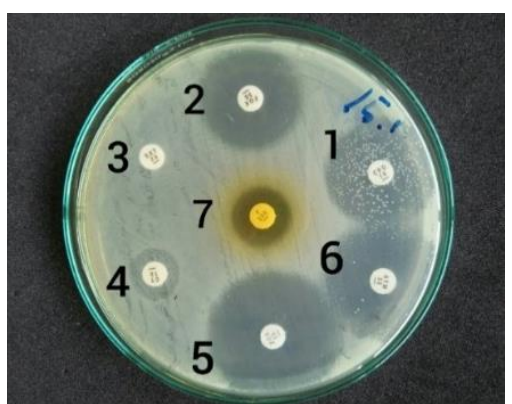

Gambar 1. Hasil uji kepekaan E. coli terhadap antibiotik sefpodoksim (1), sefoksitin (2), sulfametoksazol-trimetoprim (3), kolistin sulfat (4), seftizoksim (5), aztreonam (6), dan

nitrofurantoin (7).

Hasil pengujian kepekaan menunjukkan $87,5 \%$ isolat $E$. coli yang diuji bersifat resisten terhadap sefpodoksim, sefoksitin, seftizoksim dan aztreonam. Hal tersebut terkait dengan E. coli merupakan bakteri penghasil Extended Spectrum Beta-Lactamase (ESBL) yang memiliki kemampuan untuk menghidrolisis cincin membran beta-lactam (Carattoli 2008).

Tabel 1 Persentase kepekaan E. coli terhadap antibiotik

\begin{tabular}{|c|c|c|c|c|c|c|c|}
\hline \multirow{2}{*}{ No } & \multirow{2}{*}{ Antibiotik } & \multirow{2}{*}{$S$} & \multirow{2}{*}{ I } & \multirow{2}{*}{$\mathrm{R}$} & \multicolumn{3}{|c|}{ Persentase $(\%)$} \\
\hline & & & & & $\mathrm{S}$ & I & $\mathrm{R}$ \\
\hline 1 & Sefpodoksim & 1 & 0 & 7 & 12,5 & 0 & 87,5 \\
\hline 2 & Sefoksitin & 1 & 0 & 7 & 12,5 & 0 & 87,5 \\
\hline 3 & $\begin{array}{l}\text { Sulfametoksazol- } \\
\text { trimetoprim }\end{array}$ & 0 & 0 & 8 & 0 & 0 & 100,0 \\
\hline 4 & Kolistin Sulfat & - & - & - & - & - & - \\
\hline 5 & Seftizoksim & 1 & 0 & 7 & 12,5 & 0 & 87,5 \\
\hline 6 & Aztreonam & 1 & 0 & 7 & 12,5 & 0 & 87,5 \\
\hline 7 & Nitrofurantoin & 4 & 0 & 4 & 50,0 & 0 & 50,0 \\
\hline
\end{tabular}

Keterangan: R= Resisten; I= Intermediet; $\mathrm{S}=$ Sensitif

Sifat resisten $100 \%$ diperlihatkan oleh isolat E. coli yang diuji terhadap sulfametoksazol-trimetoprim. Hasil resistensi dapat dikarenakan isolat yang diperoleh dari ayam broiler akibat pemakaian antibiotik sebagai imbuhan pakan. Bahri et al. (2005) menyatakan 71,43\% pabrik pakan dikabupaten dikabupaten Bogor, Cianjur, Tangerang, Bekasi dan Sukabumi menambahkan antibiotika golongan tetrasiklin dan sulfonamid pada pakan. Silbegerd et al. (2008) juga menyatakan bahwa penambahan antibiotik dalam pakan merupakan faktor utama terjadinya peningkatan kejadian resistensi bakteri terhadap antibiotik.

Hasil uji isolat E. coli terhadap nitrofurantoin menunjukkan $50 \%$ E. coli yang diuji mengalami resistensi. Nitrofurantoin bekerja dengan menonaktifkan flavopro-tein pada bakteri. Akibat dari inaktivasi ini, proses biokimia bakteri terhambat (Sandegren et al. 2008).

Hasil dari pengujian kolistin sulfat tidak dapat ditunjukkan. Tan \& Ng (2006) melaporkan bahwa metode difusi cakram adalah metode pengujian sensitivitas yang tidak dapat dipertanggungjawabkan untuk golongan polimiksin. Menurut Gales et al. (2001), karakteristik difusi agar kolistin buruk, sehingga membatasi akurasi prediksi difusi cakram sehingga harus dikonfirmasi kembali dengan pengukuran Minimum Inhibitory Concentration (MIC).

\section{- SIMPULAN}

Hasil uji kepekaan isolat $E$. coli menunjukkan bahwa isolat E. coli dalam penelitian ini telah resisten terhadap sefpodoksim, sefoksitin, sulfametoksazol-timetropim, seftizoksim, aztreonam, dan nitrofurantoin. Namun tidak menunjukkan hasil terhadap kolistin sulfat.

\section{INFORMASI PENULIS}

Penulis untuk Korespondensi

*UA: uafiff60@gmail.com

Divisi Mikrobiologi Medik, Departemen Ilmu Penyakit Hewan dan Kesehatan Masyarakat Veteriner, Fakultas Kedokteran Hewan, Institut Pertanian Bogor. Jl. Agatis Kampus IPB Dramaga Bogor 16680, Jawa Barat, Indonesia.

\section{- PUSTAKA ACUAN}

[CLSI] Clinical and Laboratory Standards Institute. 2018. Performance standards for antimicrobial susceptibility testing. Wayne (US): Clinical and Laboratory Standards Institute.

Bahri S, Masbulan E, Kusumaningsih A. 2005. Proses praproduksi sebagai faktor penting dalam menghasilkan produk ternak yang aman untuk manusia. Jurnal Litbang Pertanian. 24(1): 27-35.

Carattoli A. 2008. Animal reservoirs for extended spectrum $\beta$-lactamase producers. Clinical Microbiology and Infection. 14: 117-123.

Erfianto GI. 2014. Escherichia coli yang resisten terhadap antibiotik yang diisolasi dari sapi potong yang diimpor melalui pelabuhan Tanjung Priok Jakarta [Tesis]. Bogor (ID): Institut Pertanian Bogor.

Gales AC, Reis AO, Jones RN. 2001. Contemporary assessment of antimicrobial susceptibility testing methods for polymyxin B and colistin: review of available interpretative criteria and quality control guidelines. Journal of clinical microbiology. 39(1): 183-190.

Markey B, Leonard F, Archambault M, Cullinane A, Maguire D. 2013. Clinical Veterinary Microbiology. 2nd Ed. London (UK): Mosby Elsevier.

Noviana H. 2004. Pola kepekaan antibiotika Escherichia coli yangdiisolasi dari berbagai spesimen klinis. Jurnal Kedokteran Trisakti. 23(4): 122-126.

Refdanita MR, Nurgani A, Endang P. 2004. Pola kepekaan kuman terhadap antibiotika di ruang rawat intensif Rumah Sakit Fatmawati Jakarta tahun 2001-2002. Makara, Kesehatan. 8(2): 41-48.

Sandegren L, Lindqvist A, Kahlmeter G, Andersson DI. 2008. Nitrofurantoin resistance mechanism and fitness cost in Escherichia coli. Journal of Antimicrobial Chemotherapy. 62(3): 495503.

Silbergeld EK, Graham J, Price LB. 2008. Industrial food animal production, antimicrobial resistance, and human health. Annu. Rev. Public Health. 29: 151-169.

Tan TY, Ng LS. 2006. Comparison of three standardized disc susceptibility testing methods for colistin. Journal of Antimicrobial Chemotherapy. 58(4): 864-867. 